\title{
Gastroenteritis: a waterborne outbreak affecting 1600 people in a small Danish town
}

\author{
Elle Laursen, Ole Mygind, Bent Rasmussen, Tove Rønne
}

\begin{abstract}
Study objective - To examine (i) the extent of illness caused by contamination of a waterworks with waste water due to overflow, and its correlation with precipitation; (ii) the potential secondary spread; (iii) economic losses due to sick leave.

Design - A historical follow up study with structured postal questionnaires.

Setting - A small community on the outskirts of greater Copenhagen at the end of 1991 and the beginning of 1992.

Participants - The main study group comprised all 703 households supplied by the waterworks (response rate: $89 \%$ of households). There was a control group of $\mathbf{2 0 0}$ randomly chosen households in neighbouring communities with a different water supply source (response rate: $64 \%$ of households). A day care group of all 149 children (response rate: $78 \%$ ) and 30 teachers (response rate: $83 \%$ ) who lived in central Copenhagen, but spent the day in four day care centres supplied by the waterworks, and members of their household was also studied.
\end{abstract}

Measurements and main results - Altogether 1455 people $(88 \%$ of respondents in the main study group) reported having had symptoms of gastroenteritis, particularly diarrhoea (83\%) and vomiting (55\%). In the control group, $10 \%$ had had symptoms of gastroenteritis. The onset of episodes with diarrhoea correlated well with precipitation (Spearman's correlation coefficient: $0.75 ; p=0.0002$ ). The secondary attack rate in household contacts was $12 \%$. No pathogens were found. Affected people stayed home from work for a total of 1658 days. The cost of loss of production because of sick leave amounted to 1600000 Danish kroner ( $£ 180000)$.

Conclusions - The outbreak caused ex-

Public Health Office, Frederiksborg County, Hillerød, Denmark E Laursen

B Rasmussen

Department of Epidemiology, Statens Seruminstitut, Copenhagen, Denmark

Denmark

Tove Rønne

Correspondence to: Dr E Laursen, National Board of Health, Amaliegade 13
PO Box 2020 1012 Copenhagen $\mathrm{K}$ Denmark.

Accepted for publication December 1993 tensive illness correlated with precipitation, showed secondary spread, and was associated with major economic losses. Increased awareness among local physicians and waterworks personnel of the possibility of contamination of the water could have led to earlier intervention and reduced the extent of illness. Outbreaks are often caused by several factors, many of a technical nature, which in this case acted together. It is recommended that attention be paid to each factor.

( $(\mathcal{F}$ Epidemiol Community Health 1994;48:453-458)
Almost all of the Danish supply of raw water comes from groundwater sources. ${ }^{1}$ This may explain why waterborne disease outbreaks are rarely seen here. The slow, continuous deterioration of the sewerage system does, however, mean that there is a risk of contamination of water supplies.

This report concerns a major outbreak of gastroenteritis with secondary spread that affected about 1600 people in a small Danish town. The outbreak was caused by a congested municipal sewer and by technical defects in a privately owned waterworks. Several episodes of gastroenteritis occurred, because of intermittent exposure correlated with the amount of precipitation.

Epidemiological background, events, and measures

The outbreak occurred in the small town of Uggeløse, northwest of the greater Copenhagen area. The region contains no major industries. The privately owned drinking water treatment plant supplied 703 households in the community with water. A few households in the community had private wells. In addition, the plant distributed water to four day care centres catering for a total of 149 children aged 3-6 years. The children lived in central Copenhagen but were taken by bus each day to the more rural surroundings.

The waterworks distributed its water through two wells after aeration and filtration without chlorination. The two wells were usually used for one week at a time. Well no 2 (86 $\mathrm{m}$ deep) was located approximately $8 \mathrm{~m}$ south of a municipal sewer and $14 \mathrm{~m}$ east of an old waterworks building that was no longer in use (see fig 1).

In December 1991 and January 1992, heavy rainfall caused a backflow of sewage into the old waterworks building. The backflow was caused by blockage of the village sewer by penetrating roots. The water short-circuited the electrical pump in the building, which caused the water level to rise and leak into an installation pit on well no 2 through a drainage pipe (see fig 1). The gasket at the head of the casing of the well, initially believed to be waterproof, proved defective, thereby enabling intruding sewage to pollute the well.

Pollution of the well was not suspected until Thursday, January 9, 1992, when water was found in the old waterworks building. The well was immediately closed, but no water sample was obtained until the following day. After the weekend, on Monday, January 13, the county public health office was contacted for the first 




Figure 1. Diagram of the waterworks and surroundings.

time and was informed that the sample contained 1600 total coliforms per $100 \mathrm{ml}$, of which 920 were thermotolerant.

An order to boil drinking water was issued immediately to each household as well as announced on the local radio. A few days later, filters were changed, and chlorination of filters and pipes was started. After about four weeks the water was again without pathogenic microorganisms.

It became clear that many inhabitants had suffered from intermittent gastrointestinal disease since late December 1991.

\section{Methods}

In collaboration with the Department of Epidemiology at Statens Seruminstitut, an epidemiological investigation was carried out by the county public health office.

\section{MAIN STUDY GROUP}

In early February 1992, structured questionnaires were posted to all 703 households supplied by the waterworks. Each household member was asked questions about demographic status, consumption of water, symptoms of gastroenteritis, physician contacts, and sick leave during the seven week period of 16 December 1991 to 2 February 1992. Local physicians believed that some people had had symptoms more than once during the observation period; hence for each occurrence of diarrhea, vomiting, and fever, we asked, respectively, for the date of the start and length of each episode. When calculating incidence and prevalence rates, people who had been out of the area for one or more nights were substracted from the total.

\section{CONTROL GROUP}

Questionnaires were also mailed to a control group of 200 households randomly chosen from the telephone directory in two neighbouring communities. These households received their water from different sources.
DAY CARE GROUP

All 149 children and 30 teachers at the four day care centres, and their families, were asked to fill in questionnaires. These data helped to provide information about secondary spread, as the families of the children and teachers had not drunk the contaminated water.

One reminder was sent to those who did not answer the questionnaires.

\section{INVESTIGATIONS}

Discharge summaries were obtained for those admitted to hospital. Faecal samples were examined for Salmonella, Shigella, Campylobacter and Yersinia enterocolitica at the Department of Bacteriology at Statens Seruminstitut and at the Department of Clinical Microbiology at Herlev University Hospital. Microscopical investigations for parasites were carried out locally at the Department of Clinical Microbiology at Hillerød Central Hospital; samples from the day care group were examined at several different hospitals in greater Copenhagen. A water sample, taken before chlorination, was analysed at Statens Seruminstitut.

\section{STATISTICAL ANALYSIS}

The following tests were used for statistical analysis: $\chi^{2}$, Mann-Whitney, Spearman's, and Fisher's test. A p value of 0.05 was considered significant.

\section{Results}

RESPONSE RATE

Completed questionnaires were returned from $83 \%$ of the households in the main study group. After one reminder this increased to $89 \%$, corresponding to 626 households with a total of 1647 persons. Altogether 128 households in the control group (64\%) with a total of 318 household members returned completed questionnaires. In the day care group, completed questionnaires were returned for 116 children $(78 \%)$ and 25 teachers $(83 \%)$.

\section{DEMOGRAPHIC CHARACTERISTICS}

The respondents in the main study group had a median age of 39 years (interquartile range: $19-52$ years) with a male:female ratio of 1.004 . There was no difference between the respondents in the main study group and the control group with regard to age distribution $(p=0.53)$ or gender $(p=0.24)$. There was neither a tendency towards a greater percentage of ill individuals in large households compared with smaller ones nor in households close to the waterworks compared with more distantly located households.

\section{SYMPTOMS}

A total of 1455 people ( 726 females and 729 males) from 605 households in the main study group reported gastrointestinal disease with at 
Table 1 Rainfall and cases of diarrhoea between 16 December 1991 and 2 February 1992

\begin{tabular}{|c|c|c|c|}
\hline \multicolumn{2}{|l|}{ Date } & $\begin{array}{l}\text { Rainfall } \\
(\mathrm{mm})\end{array}$ & $\begin{array}{l}\text { Incidence of diarthoea } \\
\text { (per 1000) }\end{array}$ \\
\hline \multirow{16}{*}{$\begin{array}{l}\text { 1991: } \\
\text { December }\end{array}$} & 16 & 1.0 & 5 \\
\hline & 17 & 0 & 8 \\
\hline & 18 & $11 \cdot 0$ & 8 \\
\hline & 19 & $3 \cdot 2$ & 7 \\
\hline & 20 & $5 \cdot 7$ & 17 \\
\hline & 21 & $2 \cdot 8$ & 11 \\
\hline & 22 & 1.0 & 6 \\
\hline & 23 & 4.5 & 16 \\
\hline & 24 & $15 \cdot 3$ & 11 \\
\hline & 25 & 0 & 13 \\
\hline & 26 & $5 \cdot 2$ & 21 \\
\hline & 27 & $4 \cdot 6$ & 34 \\
\hline & 28 & 0 & 39 \\
\hline & 29 & 0 & 25 \\
\hline & 30 & 0.6 & 27 \\
\hline & 31 & 0 & 17 \\
\hline \multirow{31}{*}{ 1992: January } & 1 & 0 & 15 \\
\hline & 2 & 1.7 & 22 \\
\hline & 3 & 0.3 & 25 \\
\hline & 4 & $6 \cdot 1$ & 39 \\
\hline & 5 & $2 \cdot 0$ & 79 \\
\hline & 6 & 0 & 89 \\
\hline & 7 & $0 \cdot 2$ & 66 \\
\hline & 8 & 0 & 52 \\
\hline & 9 & $6 \cdot 6$ & 35 \\
\hline & 10 & $2 \cdot 0$ & 59 \\
\hline & 11 & 0 & 66 \\
\hline & 12 & 0 & 47 \\
\hline & 13 & 0 & 45 \\
\hline & 14 & 0.4 & 21 \\
\hline & 15 & 0 & 16 \\
\hline & 16 & 0 & 11 \\
\hline & 17 & 0 & 9 \\
\hline & 18 & 0 & 7 \\
\hline & 19 & $7 \cdot 7$ & 2 \\
\hline & 20 & $7 \cdot 7$ & 5 \\
\hline & 21 & 0 & 3 \\
\hline & 22 & 0 & 2 \\
\hline & 23 & 0 & 2 \\
\hline & 24 & 0 & 2 \\
\hline & 25 & 0 & 4 \\
\hline & 26 & 0 & 1 \\
\hline & 27 & 0 & 2 \\
\hline & 28 & 0.3 & 2 \\
\hline & 29 & 0.4 & 2 \\
\hline & 30 & 0 & 4 \\
\hline & 31 & 0.3 & 2 \\
\hline \multirow{2}{*}{ February } & 1 & 0.1 & 2 \\
\hline & 2 & 0 & 1 \\
\hline
\end{tabular}

least one of the three symptoms of diarrhoea, vomiting, or fever during the seven week observation period from 16 December 1991 to 2 February 1992. This corresponds to $88 \%$ of those who returned the questionnaires. There was no difference between males and females $(p=0.95)$. Between 80 and $100 \%$ fell ill in each five year age group. Guests visiting the area, as well as residents returning home from holidays, reported a typical incubation time of from one to three days. This is illustrated in figure 2 . In the control group, $10 \%$ of respondents reported gastroenteritic symptoms during the observation period.

\section{Diarrhoea}

Eighty three per cent of respondents in the main study group reported having had diarrhoea at least once during the observation period. Table 1 shows, day by day, the amount of rainfall in the area and the incidence rate of diarrhoea, that is, the number of people who reported diarrhoea per 1000 respondents. These data are presented graphically in figure 2 . Data on the incidence of diarrhoea in the control group have been added to the figure.

It can be seen that between 19 and $24 \mathrm{De}-$ cember only a few (but significantly more than in the control group $(p=0.0001))$ reported diarrhoea despite rather heavy rainfall around 18-20 December. After even heavier rainfall on 24 December, and lighter rainfall around 26-27 December, the number who fell ill increased to $30-40$ per 1000 at the end of the month and decreased again around 1 January. After a new but moderate rainfall on 4 January, the number who contracted diarrhoea peaked - with 65-90 per 1000 starting an episode of diarrhoea on 5, 6, and 7 January. After still another rainfall on 9 January, the reported number of diarrhoea episodes again increased.

On 9 January, water contamination was suspected (the floor of the old waterworks building had been flooded), and well no 2 was closed. This well had been in use from the start of the observation period (December 16) except for a one week period from 27 December to 3 January.

The number of individuals who reported diarrhoea gradually decreased from the last peak on 11 January, and further heavy rainfall around 19-20 January caused no increase in illness.

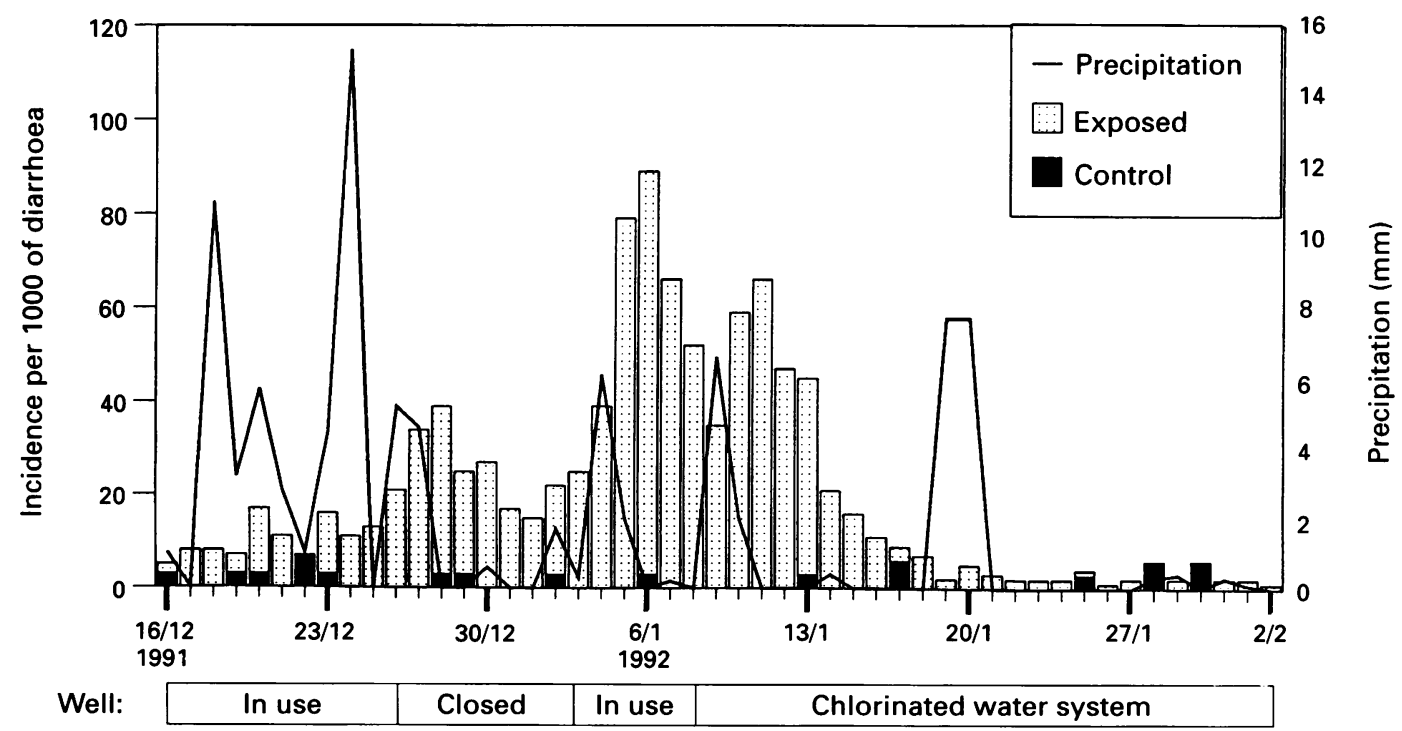

Figure 2. Daily incidences of diarrhoea and precipitation between 16 December 1991 and 2 February 1992 in main study (exposed) and control groups. 


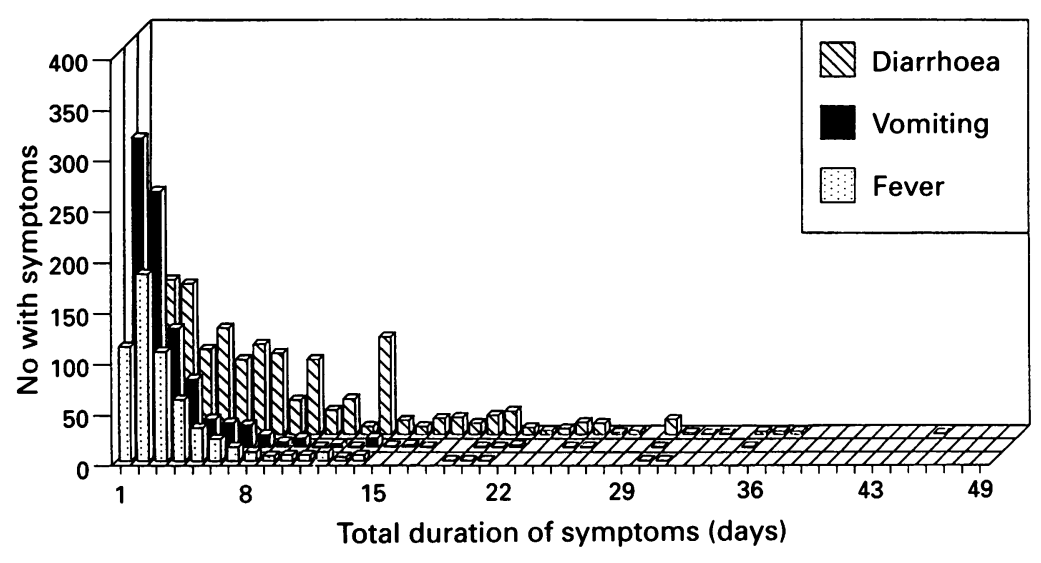

Figure 3. Number of persons with symptoms of diarrhoea, vomiting, and fever in relation to the total duration of symptoms between 16 December 1991 and 2 February 1992. abdominal cramps, and changes in stool colour. Seven per cent reported skin symptoms (rash and skin irritation).

\section{Duration of symptoms}

Figure 3 shows the number of people with each of the three symptoms (diarrhoea, vomiting, and fever) according to their total duration. The total average (mean) duration of diarrhoea was 8.5 days (median 6 days, interquartile range $3-12$ days), of vomiting $3 \cdot 1$ days (median 2 days, interquartile range $1-3$ days), and of fever 3.5 days (median 2 days, interquartile range 2-4 days). No protracted symptoms were observed.

Corresponding data for the control group showed an average (mean) duration of diarrhoea of 2.8 days (median 2 days, interquartile range 2-3 days), of vomiting 1.7 days (median 1.5 days, interquartile range 1-2 days), and of fever $2 \cdot 3$ days (median 2 days, interquartile range 1-2 days). The difference between the main study and the control groups was significant for both diarrhoea and vomiting $(p<0 \cdot 05)$, but not for fever $(p=0 \cdot 20)$. 0.0002). For this calculation we have chosen to set daily precipitation for the four days preceding 25 December (December 2124) to zero, assuming that the heavy precipitation on 24 December was the event that caused the final breakdown of the sewerage system. The sewer probably started to become congested by intruding roots before $24 \mathrm{De}$ cember, however, meaning that smaller amounts of waste water leaked into the well. Well no 3 was in use between 27 December and 3 January, which meant that the pipe system was flushed with uncontaminated water: this probably accounted for the decrease in new cases of diarrhoea around 31 December.

Between 7 and 14 January, prevalence rates for diarrhoea ranged between 301 and 341 per 1000 , reaching a maximum of 341 per 1000 on 11 January.

\section{Other symptoms}

Fifty five per cent of respondents experienced vomiting, and $39 \%$ reported having had fever at least once during the observation period. Analysis of incidence and prevalence rates for these two other gastrointestinal symptoms shows a similar correlation with precipitation as diarrhoea. Of those who reported diarrhoea, $61 \%$ also reported vomiting. Of those reporting vomiting, $91 \%$ also cited diarrhoea.

In an open ended question, respondents were asked to report symptoms other than diarrhoea, vomiting, and fever. The gastrointestinal symptoms mentioned included anorexia, nausea,

Table 2 Percentage of respondents who reported symptoms of gastroenteritis (diarrhoea, vomiting, fever) in relation to usual daily consumption of tap water

\begin{tabular}{ll}
\hline Usual consumption of water/d & $\begin{array}{l}\text { \% reporting } \\
\text { symptoms }\end{array}$ \\
\hline None $(\mathrm{n}=100)$ & 67 \\
Less than 1 glass $(\mathrm{n}=290)$ & 82 \\
At least 1 glass $(\mathrm{n}=1236)$ & 93 \\
\hline
\end{tabular}

Symptoms in relation to water consumption

With increasing daily consumption of tap water we found an increase in the proportion falling ill, as shown in table 2. This correlation was significant $(p<0.00001)$ using a Mann-Whitney test. For the control group no significant correlation was found between water consumption and illness. Few people consumed boiled tap water; instead water was brought home from the work place, family or friends from outside the area, or purchased as bottled water.

PHYSICIAN CONTACTS

Around $17 \%$ of those who fell ill called a physician, and $8 \%$ were examined by one. Ten individuals (less than $1 \%$ ) were admitted to a hospital. Two underwent an appendectomy; one of these had an inflamed appendix. No one died.

\section{ABSENCE FROM WORK}

A total of 499 people in the main study group had to remain home from work for a total of 1658 days either because of their own symp(173 days). This corresponds to a loss of production amounting to almost 1600000 Danish kroner $(£ 180000)$. In the control group 12 people had to stay at home for 28 days because of their own illness ( 23 days) or their children's illness (5 days).

\section{SECONDARY SPREAD}

Eighty one children ( $70 \%$ of responding children) and 20 teachers ( $80 \%$ of responding teachers) in the day care group fell ill. Fifty seven of their family members $(22 \%$ of responding family members) contracted gastroenteritis. The family members had not drunk toms ( 1485 days) or to take care of sick children 
the polluted water. By subtracting the percentage of individuals who fell ill in the control group (10\%), a secondary attack rate of approximately $12 \%$ can be calculated. In addition, 692 persons reported having fallen ill after visiting the area during the observation period. Neither the water consumption of these visitors while in the area nor the total number of visitors is known. Their symptoms may thus be caused by intake of contaminated water or by secondary spread.

\section{MICROBIOLOGY}

Examination of samples of faeces for standard pathogenic intestinal bacteria (Salmonella, Shigella, Campylobacter and Yersinia enterocolitica) revealed only one specimen that contained a pathogenic agent, Yersinia. Since this finding was not reproduced in other specimens, we have interpreted it as having no significance to the waterborne outbreak. Microscopical examinations revealed no parasites. Examination of faecal samples from two 1 year olds for Rotavirus proved negative.

A germ count performed on a water sample taken before chlorination showed 32 aerobic colony forming units (CFU)/ml, 5 anaerobic $\mathrm{CFU} / \mathrm{ml}, 4$ enterobacteriae $/ \mathrm{ml}$ and $<10$ psychotrophic (cold tolerant $\left(5^{\circ} \mathrm{C}\right)$ ) $\mathrm{CFU} / \mathrm{ml}$. Unfortunately, no further analysis was attempted.

\section{Discussion}

Before 1980 Denmark had no centralised reporting of waterborne disease outbreaks. In attempting to collect information about pre1980 outbreaks, several different sources must be searched which makes it difficult to compare Denmark with other countries.

During the last decades only two large Danish outbreaks have been reported. One of these occurred in a large provincial town in 1979 and affected 2000-3000 people. Contamination of drinking water was caused by a combination of three factors:

(1) Heavy precipitation caused overflow from the sewerage system and filled an installation pit on a low-lying well;

(2) Waste water from this pit then had made its way to a drinking water tank through a normally closed valve;

(3) The level of water in the drinking water tank was exceptionally low. ${ }^{2}$

An outbreak in a military barracks in 1987 caused gastroenteritis among 200-300 recruits and employees. The outbreak was caused by a technical defect in a nearby sewage treatment plant. Due to this defect, sewage was introduced directly into the drinking water pipe system. $^{3}$

The outbreak we described here was caused by a combination of factors (see fig 1):

(1) Blockage of the municipal sewer by intruding roots, causing ... .

(2) Backflow of sewage into the old waterworks building through a pipe, which resulted in the water rising in the building and thereby shortcircuiting the electrical pump; this produced ...
(3) Further backflow of sewage from the waterworks building into an installation pit on well no 2 through a drainage pipe, and

(4) A defective gasket at the head of the casing of well no 2 .

Both the local authorities and the waterworks management were aware of the drainage pipe from the installation pit. In 1990 local authorities had asked the waterworks if there was a risk of backflow of sewage to the pit through this drainage pipe, but their inquiry went unanswered. Drainage pipes from installation pits have not been allowed since 1980 , as correctly constructed installation pits are assumed to be dry even where there is no drainage.

An outbreak in 1982, attributed to causes similar to those described here, has been reported from Sweden. ${ }^{4}$ In a Swedish review article of waterborne outbreaks, the most frequent technical deficiency resulting in outbreaks from groundwater sources was the intrusion of waste water or polluted surface water at the source or reservoir. In six cases (out of 26) there was blockage of waste water pipes resulting in inverse flow. ${ }^{5}$

It can be concluded that an outbreak is often caused by several factors acting together. It is important to pay attention to seemingly minor defects, even though large expenses may be incurred in connection with correcting these defects.

As a consequence of the present outbreak, the gasket at the head of the casing has been changed, the drainage pipe between the well and the old waterworks has been disconnected, and $400 \mathrm{~m}$ of sewers alongside the waterworks have been renovated at a price of 600000 Danish kroner ( $£ 65000)$. Authorities have discussed whether to close well no 2 and establish a new one which would cost around 400000 Danish kroner $(£ 45000)$. This amount should be compared to the value of lost production due to sick leave (1600000 Danish kroner $(£ 180000))$. In addition the accident resulted in other expenditure, covered partly by the public authorities, partly by the exposed persons themselves.

During the last couple of years, Danish public authorities and politicians have become more aware of the deterioration of the sewerage system, and various measures have been taken to improve them. The county's 19 municipalities have been urged by the county public health office to pay special attention to the conditions of wells located close to sewers. The Danish Environmental Protection Agency has subsequently sent a letter to all Danish municipalities with a similar request.

No other waterborne disease in Denmark has been as thoroughly studied as the present one. Of particular importance is the correlation between precipitation and the onset of reported gastrointestinal symptoms. Figure 2 convincingly demonstrates how the intrusion of sewage into well no 2 was followed, within a few days, by an increase in onset of diarrhoea. To our knowledge, such a close correlation between precipitation and disease onset has not been reported in other studies. 
The attack rate among household contacts of the children in the day care institutions was approximately $12 \%$. A similar attack rate has been found among household contacts of visitors to a resort camp where a viral aetiology for gastroenteritis was suspected. ${ }^{6}$ That secondary person to person spread occurred within the local families may be suspected by the finding that $67 \%$ of those who reported no daily intake of tap water fell ill. This may be due to use of non-boiled water in cooking, brushing teeth, showering, or, possibly, secondary spread among family members.

It is well known ${ }^{578}$ that in about half of all waterborne outbreaks no causative organism(s) are found. In a recent review of causes of waterborne disease outbreaks in Sweden during 1980-89, despite examination of both water and faecal samples, pathogens were found in only $20 \%$ of outbreaks. ${ }^{9}$ This study has eliminated parasites as well as four bacteria (Salmonella, Shigella, Campylobacter and Yersinia enterocolitica) from having been causative agents. Based on the findings (an incubation time of a few days, a high frequency of reported vomiting and particularly diarrhoea, as well as secondary spread), we find a viral aetiology most plausible. Possibly more than one viral pathogen may have been present, as sewage contamination of water may involve various micro-organisms. ${ }^{6}$

No search was made for possible chemical agents. Skin symptoms, reported by $7 \%$ of the respondents, may have been caused by either microbiological or chemical pollutants.

In Denmark water (and food) borne diseases are notifiable in writing to the country public health office, the Department of Epidemiology at Statens Seruminstitut, and the National
Board of Health. In the event of an accumulation of cases of waterborne diseases, they must also be reported by phone to the county public health office. It is important that even suspicion of waterborne diseases is reported in order to limit the number of future cases.

In the present outbreak, the local physicians had noticed an increased number of cases of gastroenteritis in the community but had not considered the water supply as a possible aetiological agent, as waterborne disease outbreaks are very rare in Denmark. The county public health office was not informed of the increased number of cases of gastroenteritis. Had the office been informed by local physicians or by the local authorities, as soon as pollution of the well was suspected, a considerable amount of excess morbidity would have been avoided.

1 Bonde GJ. Water quality and health. General report 1. Proceedings of the 13th Congress of the International Water Supply Association (IWSA). Paris, 1980:A1-A19.

2 Steensberg, J. Environmental health decision making. The politics of disease prevention. Scand $\mathcal{f}$ Soc Med 1989; 42(suppl):45-6.

3 Hansen A. Akut gastroenteritis (Acute gastroenteritis). Ugeskr Laeger 1987;149:3360-1.

4 Neringer R, Andersson Y, Eitrem R. A water-borne outbreak of Giardiasis in Sweden. Scand $\mathcal{F}$ Infect Dis 1987;19:85-90.

5 Andersson Y, Stenström TA. Waterborne outbreaks in Sweden - causes and etiology. Water Science and Technology 1987;19:575-80.

6 Morens DM, Zweighaft RM, Vernon TM, et al. A waterborne outbreak of gastroenteritis with secondary person-to-person spread. Lancet 1979;i:964-6.

7 Centers for Disease Control. Waterborne disease outbreaks, 1989-1990. MMWR 1991;40(SS-3):1-21.

8 Lippy EC, Waltrip SC. Waterborne disease outbreaks - 19461980: A thirty-five-year perspective. $\Im A W W A$ 1984; 76:60-7.

9 Andersson Y. Dricksvattenburna sjukdomsutbrott $i$ Sverige $-i$ ett historiskt, hygieniskt och tekniskt perspektiv (Outbreaks of water-borne disease in Sweden in historical, hygienic and technical perspective). (MPH thesis.) Gothenburg: The Nordic School of Public Health, 1992. 